\title{
The Indian Ocean Dipole as an indicator of climatic conditions affecting European birds
}

\author{
Piotr Tryjanowski ${ }^{1, *}$, Nils Chr. Stenseth ${ }^{2}$, Beata Matysioková ${ }^{3}$ \\ ${ }^{1}$ Institute of Zoology, Poznań University of Life Sciences, 60-625 Poznań, Poland \\ ${ }^{2}$ Centre for Ecological and Evolutionary Synthesis (CEES), Department of Biosciences, University of Oslo, 0316 Oslo, Norway \\ ${ }^{3}$ Department of Zoology and Laboratory of Ornithology, Palacký University, 77146 Olomouc, Czech Republic
}

\begin{abstract}
Variation in large-scale climatic conditions can have profound effects on local weather patterns and ecological processes. For example, it is well known that a positive shift in the North Atlantic Oscillation (NAO) during the last 2 decades has coincided with warmer, wetter winters over Northern Europe and advances in spring phenology, including both migration and breeding of birds. However, the effect of the NAO is not evident throughout the Northern Hemisphere and the same is true of the El Niño-Southern Oscillation (ENSO), which has been linked to survival of northern birds wintering in Africa. Recently, a growing body of evidence suggests that an independent ocean circulation system in the Indian Ocean, the Indian Ocean Dipole (IOD), is partly responsible for driving climate variability in the surrounding landmasses. The IOD had traditionally been viewed as an artefact of the ENSO system, although increasingly evidence is accruing that it is a separate and distinct phenomenon. Here we present some results on the causes of the IOD, how it develops within the Indian Ocean, its relationships with the ENSO, and the consequences for East African climate dynamics and associated impacts on ecosystems, in particular along the Eastern Arc Mountains of Kenya and Tanzania. In this opinion article we evaluate current research initiatives focused on characterizing the IOD, and examine how effective these will be in determining climate change impacts on East African ecosystems, particularly with respect to avian lifecycles.
\end{abstract}

KEY WORDS: Climate changes $\cdot$ ENSO $\cdot$ Indian Ocean Dipole $\cdot$ IOD $\cdot$ Migratory path $\cdot$ Large-scale indices $\cdot \mathrm{NAO} \cdot$ Spatial-temporal changes

\section{INTRODUCTION}

Climate changes in recent decades have had a strong documented worldwide impact on ecosystems and organisms, with the greatest impact on phenology (Walther et al. 2002). Plants are blooming and leafing earlier, insects have advanced their first flights or time of spring emergence, and an earlier start of reproduction has been observed in some amphibians, reptiles and mammals. Similarly in birds, which are undoubtedly the best-studied group, climate change has affected the timing of arrival at nesting sites and of breeding (Dunn 2004, Newton 2008, Knudsen et al. 2011).
Migration is a key aspect of the life histories of migratory birds (Newton 2008), and its timing is known to have an effect on their survival and reproductive performance. For example, reproductive success usually decreases with later arrival time (Dunn 2004). However, premature arrival can also be disadvantageous if ecological conditions on breeding grounds are unfavourable (Newton 2008). Similarly, birds could become ecologically mismatched if the advance in their arrival date has not fully compensated for climate change and thus the timing of arrival to the breeding grounds is not synchronized with the peak of their food source (Saino et al. 2011). In recent decades, advance in spring arrival dates of 
both short- and long-distance migrants has been observed (Knudsen et al. 2011). Advanced arrivals can thus result from earlier departure and/or quicker migration. There are several ways that climate can affect both the timing of departure and migration speed. For example, onset of migration can be determined by food availability in wintering areas (Studds \& Marra 2011, Altwegg et al. 2012), which is in turn affected by weather conditions. In this way, timing of departure can be indirectly affected by climate fluctuations. Similarly, weather conditions have an effect on the number and duration of stopovers, which in turn influence migration speed (Gordo 2007, Tøttrup et al. 2012). Moreover, favourable weather conditions (e.g. tailwinds) can increase flying speed while unfavourable weather conditions (e.g. headwinds, crosswinds, heavy rainfall) can decrease it (Richardson 1978). Hence, by influencing conditions in wintering areas and along the migration route, climate changes can influence arrival times of migratory birds (Lehikoinen et al. 2004, Both 2010).

Here we suggest that using information on the Indian Ocean Dipole (IOD) could improve understanding of the response of European birds to climate factors.

\section{LARGE-SCALE CLIMATE INDICES}

Large-scale climatic characteristics (freely available from the Internet) are often used to ascertain the relationship between climate and avian phenology. However, large-scale climate indices, by definition, are characterized by low geographical resolution (Stenseth et al. 2003). Despite the fact that over a dozen large-scale climate indices have been defined by climatologists, only the El Niño-Southern Oscillation (ENSO) and the North Atlantic Oscillation (NAO) are commonly used by ecologists (Stenseth et al. 2003).

In simple words, the ENSO is an irregular fluctuation between cold (La Niña) and warm (El Niño) phases occurring across the tropical Pacific Ocean (Latif \& Keenlyside 2009). During the warm El Niño phase, extensive rainfall (extensive drought) can be observed in the eastern (western) Pacific. The (winter) NAO is defined as the difference between the normalized sea-level pressures at the Azores and Iceland averaged over the period December-March, characterizing the meteorological situation in winter and early spring. A positive NAO phase is associated with increased temperature and precipitation in northern Europe and south-eastern North America, and drier conditions over southern Europe and the
Mediterranean (Hurrell \& Loon 1997). The effects of the ENSO can be directly observed in the climate of the subtropical and tropical Pacific Ocean while the NAO is the major cause of weather and climate fluctuation in the North Atlantic region (Stenseth et al. 2003, Latif \& Keenlyside 2009).

Phenological studies are geographically biased, and most of the studies on climate and avian phenology come from the Northern Hemisphere. Therefore, it is not surprising that the NAO is used frequently in phenology studies (reviewed in Gordo, 2007). A relationship between the NAO and avian phenology has been detected in a number of studies, especially in short-distance migrants showing advanced arrival dates in years with a positive NAO index (Hubálek 2003, Palm et al. 2009). However, this relationship was not observed in most of the studied long-distance migrants (Hubálek 2003, Palm et al. 2009, but see Hüppop \& Hüppop 2003, Horev et al. 2010). Null or weak relationships between the NAO and arrival time in long-distance migrants is often explained by the onset of migration being under stronger endogenous control in those species (Newton 2008). This could be maladaptive in a changing climate, and could become an evolutionary trap (Schlaepfer et al. 2002). However, it is possible that the timing of migration in those species is flexible and under the influence of climatic conditions in wintering areas or along the migration route, but that indices with only low predictive values are being used.

A number of species from central and eastern Europe migrate to their wintering grounds via the Balkan Peninsula and the Middle East, and winter in East Africa (Newton 2008, Shobrak 2011), where the signal of the NAO is weak (Hurrell \& Loon 1997). For example, in the Czech Republic and Slovakia $>24 \%$ of long-distance migrants with a known direction of migration $(\mathrm{n}=37$ ) migrated to their wintering grounds in Africa in a southeastern direction via the Balkan Peninsula and the Middle East (Cepák et al. 2008). Moreover, nearly $58 \%$ of Czech and Slovakian long-distance migrants $(\mathrm{n}=66$ ) wintered (at least partly) in East or Central Africa (Cepák et al. 2008). Therefore, the value of using the NAO in studies of long-distance migrants breeding in central and eastern Europe to investigate relationships between climate and avian phenology is questionable.

Birds wintering in sub-Saharan Africa are not able to predict weather conditions prevailing in Europe and to adjust departure time accordingly (Lehikoinen et al. 2004). The decision to depart is thus influenced by weather conditions at their wintering grounds in Africa rather than those prevailing at that 
time in Europe (Gordo et al. 2005, but see Saino \& Ambrosini 2008). Weather (especially precipitation) is the best predictor of biomass productivity, and thus probably also of the quality of wintering habitats in Africa (Herrmann et al. 2005). Hence, it can indirectly affect departure time and migration speed by affecting body condition of migrating individuals (Gordo 2007).

\section{THE INDIAN OCEAN DIPOLE}

Previously it was assumed that precipitation in East Africa was influenced by the ENSO (Indeje et al. 2000). However, it appears that the observed relationship between East African rainfall and the ENSO is rather a manifestation of a connection between the ENSO and the IOD (Black 2005). The IOD had traditionally been viewed as an artifact of the ENSO, but it is now considered to be independent (Saji et al. 1999, Ashok et al. 2003). It is an oscillation of sea surface temperature (SST) gradient between the western and eastern parts of the Indian Ocean. The gradient is called Dipole Mode Index (DMI). When the DMI is positive, the phenomenon is referred to as the positive IOD (and vice versa). During positive IOD events, there is above-average SST in the western Indian Ocean and lower-thanaverage SST in the eastern side. Similarly, a positive IOD is associated with higher precipitation in eastern Africa, while rainfall in Indonesia and Australia is reduced, resulting in severe drought (Saji et al. 1999). Growing evidence shows that the climate (especially precipitation) of eastern Africa is influenced by the IOD (Black 2005, Hashizume et al. 2009). By influencing precipitation, the IOD has previously been shown to have an indirect impact on, for example, malaria epidemics in western Kenya (Hashizume et al. 2009) and vegetation development in tropical East Africa (Marchant et al. 2007). The DMI data can be obtained from the Frontier Research Centre for Global Change (www. jamstec.go.jp/frcgc/research/d1/iod/e/index.html).

\section{WHY USING THE IOD COULD HELP AVIAN PHENOLOGY}

We believe that using the IOD to explain the phenology of European migratory species wintering in eastern Africa and/or migrating via the Balkan Peninsula and the Middle East would be better than the commonly used NAO. For example, climatic in- dices were repeatedly used to explain the timing of arrival at the breeding grounds of the White Stork Ciconia ciconia (Hubálek 2003, Hubálek \& Čapek 2008). However, the white stork populations in Europe are divided into populations wintering in the western Sahel and in eastern and southern Africa (Kanyamibwa et al. 1993). Despite this, the NAO was used in all studies, i.e. also in those populations wintering in eastern and southern Africa (Hubálek 2003, Hubálek \& Čapek 2008), where using the IOD could be more appropriate. Similarly, the relationship between arrival dates and the NAO was studied in 32 long-distance migrants breeding in Moravia, Czech Republic (Hubálek 2003). There was no correlation between the NAO and arrival date in most (94\%) of those species. However, $69 \%$ of the studied species winter (at least partly) in East Africa (Cepák et al. 2008). Moreover, $25 \%$ of the species for which migration route is known $(\mathrm{n}=24)$ migrate via the Middle East and the Balkan Peninsula (Cepák et al. 2008) and thus should be little affected by the NAO during most of their journey. Although, we cannot totally rule out the possible impact of spring temperatures on European longdistance migrants prevailing after they reach the European continent (Both 2010), the signal of NAO during spring is weak in central Europe (Pokorná et al. 2007).

Despite its great potential, the use of the IOD as a correlate of avian phenology is very rare, especially in comparison with the large number of studies which use the NAO and the ENSO (Fig. 1). We are aware of just 2 studies in which the IOD was used as a correlate of avian phenology. Hušek et al. (2009) studied the relationship between the timing of breeding, variance in breeding and IOD in redbacked shrikes Lanius collurio. Timing of breeding was best explained by population size and climatic conditions on breeding grounds (temperature in May). On the other hand, after accounting for the effects of covariates (number of studied nests), variance in the timing of first clutches was best predicted by the IOD (based on Akaike weights; Hušek et al. 2009) and the relationship was positive (J. Hušek pers. comm.). Differences in timing of breeding are typically explained by individual conditions of breeding birds (Verhulst \& Nilsson 2008). The positive relationship between the IOD and variability in the timing of first clutches thus suggests that the IOD can possibly influence body condition of wintering birds. In the second study, the relationship between the passage time of steppe eagle Aquila nipalensis at Eilat, Israel and the IOD was examined 

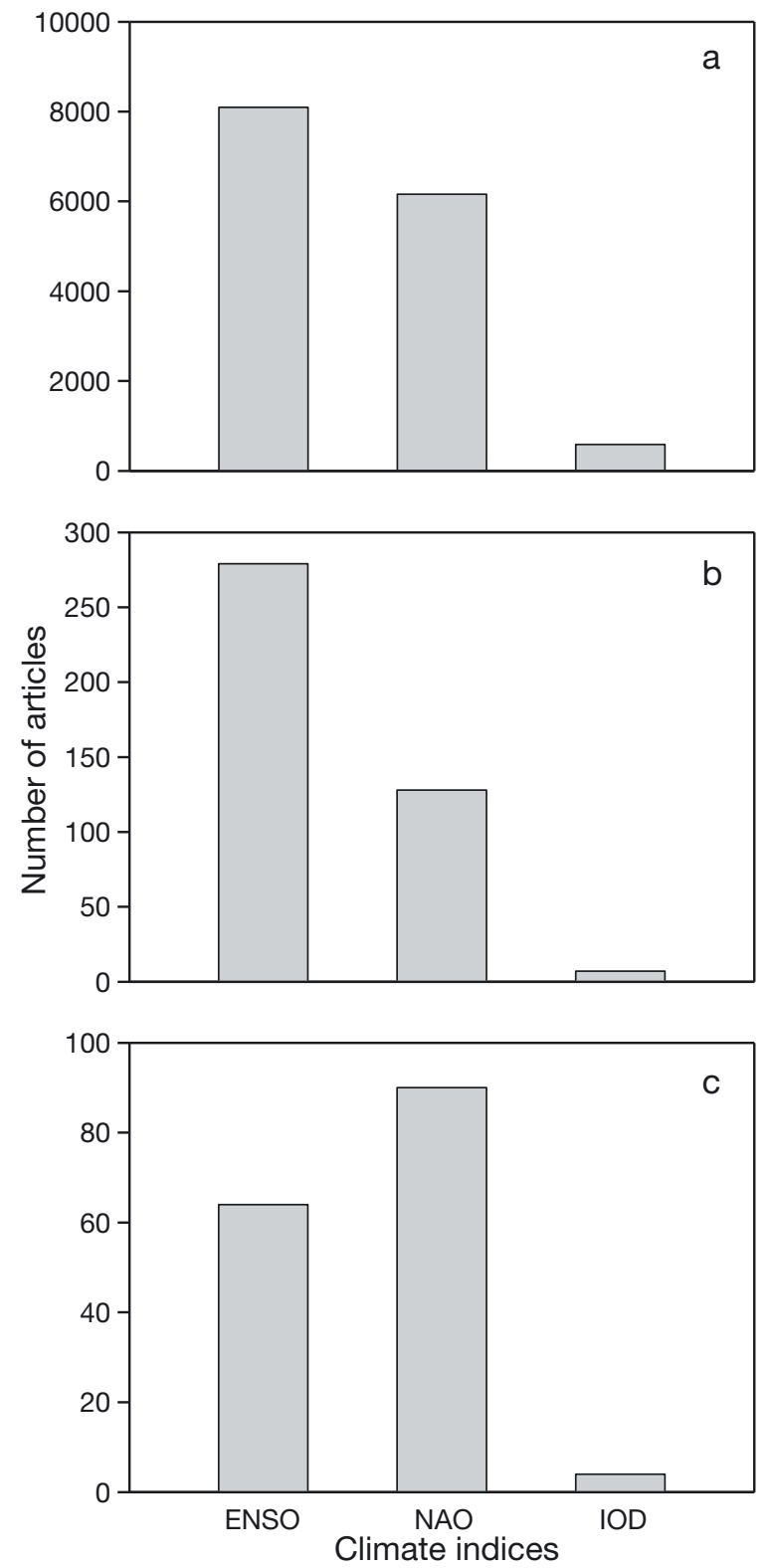

Fig. 1. Number of articles (indexed by Science Citation Index, updated 15 Apr 2012) that refer to El Niño-Southern Oscillation (ENSO), the North Atlantic Oscillation (NAO) and the Indian Ocean Dipole (IOD) by (a) mentioning them in the abstract and/or keywords, (b) linking them to ecology; and (c) linking them to avian phenology

(Zduniak et al. 2010). They did not find any significant correlation between passage phenology and the IOD. In steppe eagles, however, birds of different ages use different wintering grounds: adults winter mainly in eastern Africa and juvenile and immature birds in southern Africa (Shirihai et al. 2000), where the effect of the ENSO prevails (Ambrosino et al. 2011, Philippon et al. 2012). Hence, we speculate that different results could be obtained if we

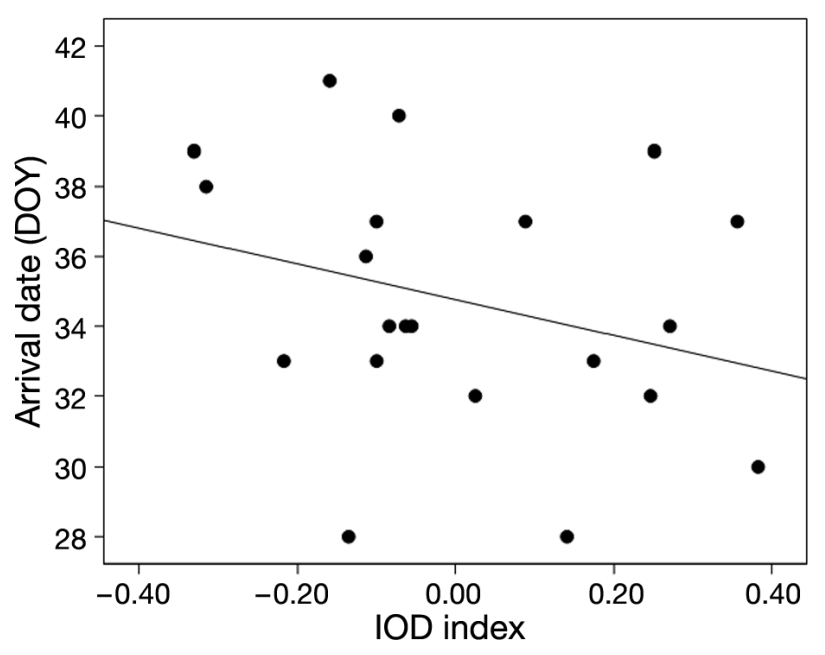

Fig. 2. Relationship between the Indian Ocean Dipole (IOD; Nov-Mar) and red-breasted flycatcher Ficedula parva arrival time (day of the year, DOY) to Bialowieza Primeval Forest in 1983-2004 $\left(\mathrm{r}_{\mathrm{s}}=-0.643, \mathrm{n}=21 \mathrm{yr}, \mathrm{p}=0.002\right)$. Data on arrival times after Mitrus et al. $(2005,2012)$. Regression line superimposed

analyzed those 2 age groups separately. We also detected a readable signal of IOD when re-analysing data on the arrival pattern of a species wintering in the Indian subcontinent, the red-breasted flycatcher Ficedula parva (Fig. 2).

\section{CONCLUSIONS}

In summary, we believe that using only the NAO or the ENSO in studies of avian phenology can miss some key existing patterns. This is especially true for birds using the eastern migratory path in Europe, when the effect of circulation patterns over the Atlantic Ocean will definitely have less influence. These indices are well recognized and have generated robust explanations of the phenology, survival patterns and population dynamics of many bird species. However, we suggest that using the neglected IOD in studies of the phenology of migrant species wintering in eastern Africa could be more appropriate. More studies are clearly necessary, investigating the link between weather conditions in breeding and wintering areas, as well as during both spring and autumn seasonal migration.

Acknowledgements. We are grateful to J. Hušek and C. Mitrus for access to raw data, to the editor, V. Remeš and 3 anonymous referees for helpful comments on the manuscript. 


\section{LITERATURE CITED}

Altwegg R, Broms K, Erni B, Barnard P, Midgley GF, Underhill LG (2012) Novel methods reveal shifts in migration phenology of barn swallows in South Africa. Proc R Soc Lond B 279:1485-1490

> Ambrosino C, Chandler RE, Todd MC (2011) Southern African monthly rainfall variability: an analysis based on generalized linear models. J Clim 24:4600-4617

Ashok K, Guan Z, Yamagata T (2003) A look at the relationship between the ENSO and the Indian Ocean Dipole. J Meteorol Soc Jpn 81:41-56

> Black E (2005) The relationship between Indian Ocean seasurface temperature and East African rainfall. Philos Trans R Soc Lond A 363:43-47

- Both C (2010) Flexibility of timing of avian migration to climate change masked by environmental constraints en route. Curr Biol 20:243-248

Cepák J, Klvańa P, Škopek J, Schropfer L and others (2008) Atlas migrace ptáků České a Slovenské republiky. Aventinum, Prague

Dunn P (2004) Breeding dates and reproductive performance. Adv Ecol Res 35:69-87

Gordo O (2007) Why are bird migration dates shifting? A review of weather and climate effects on avian migratory phenology. Clim Res 35:37-58

Gordo O, Brotons L, Ferrer X, Comas P (2005) Do changes in climate patterns in wintering areas affect the timing of the spring arrival of trans-Saharan migrant birds? Glob Change Biol 11:12-21

Hashizume M, Terao T, Minakawa N (2009) The Indian Ocean Dipole and malaria risk in the highlands of western Kenya. Proc Natl Acad Sci USA 106:1857-1862

> Herrmann SM, Anyamba A, Tucker CJ (2005) Recent trends in vegetation dynamics in the African Sahel and their relationship to climate. Glob Environ Change 15: 394-404

> Horev A, Yosef R, Pinshow B (2010) Influence of point-ofdeparture climate variables on the passage dates of two long distance migrants in Eilat. Clim Res 42:105-109

Hubálek Z (2003) Spring migration of birds in relation to North Atlantic Oscillation. Folia Zool (Brno) 52:287-298

Hubálek Z, Čapek M (2008) Migration distance and the effect of North Atlantic Oscillation on the spring arrival of birds in Central Europe. Folia Zool (Brno) 57:212-220

Hüppop O, Hüppop K (2003) North Atlantic Oscillation and timing of spring migration in birds. Proc R Soc Lond B 270:233-240

> Hurrell JW, Loon HVAN (1997) Decadal variations in climate associated with the North Atlantic Oscillation. Clim Change 36:301-326

Hušek J, Adamík P, Cepák J, Tryjanowski P (2009) The influence of climate and population size on the distribution of breeding dates in the red-backed shrike (Lanius collurio). Ann Zool Fenn 46:439-445

Indeje M, Semazzi FHM, Ogallo LJ (2000) ENSO signals in East African rainfall seasons. Int J Climatol 20:19-46

Kanyamibwa S, Bairlein F, Schierer A (1993) Comparison of survival rates between populations of the white stork Ciconia ciconia in Central Europe. Ornis Scand 24: 297-302

Knudsen E, Lindén A, Both C, Jonzen N and others (2011) Challenging claims in the study of migratory birds and climate change. Biol Rev Camb Philos Soc 86:928-946

Latif M, Keenlyside NS (2009) El Niño/Southern Oscillation response to global warming. Proc Natl Acad Sci USA 106:20578-20583
Lehikoinen E, Sparks TH, Zalakevicius M (2004) Arrival and departure dates. Adv Ecol Res 35:1-31

Marchant R, Mumbi C, Behera SK, Yamagata T (2007) The Indian Ocean dipole: the unsung driver of climatic variability in East Africa. Afr J Ecol 45:4-16

Mitrus C, Sparks TH, Tryjanowski P (2005) First evidence of phenological change in a transcontinental migrant overwintering in the Indian sub-continent: the red-breasted flycatcher Ficedula parva. Ornis Fenn 82:13-19

Mitrus C, Mitrus J, Sikora M (2012) Badge size and arrival time predict mating success of red-breasted flycatcher Ficedula parva males. Zoolog Sci 29:795-799

Newton I (2008) The migration ecology of birds. Academic Press, London

Palm V, Leito A, Truu J, Tomingas O (2009) The spring timing of arrival of migratory birds: dependence on climate variables and migration route. Ornis Fenn 86:97-108

> Philippon N, Rouault M, Richard Y, Favre A (2012) The influence of ENSO on winter rainfall in South Africa. Int J Climatol 32:2333-2347

Pokorná L, Beranová R, Huth R (2007) Vztahy mezi cirkula ními mody a klimatickými prvky v České Republice a jejich časová proměnlivost. Meteorologické zprávy 60: $65-76$

> Richardson WJ (1978) Timing and amount of bird migration in relation to weather: a review. Oikos 30(2):224-272

Saino N, Ambrosini R (2008) Climatic connectivity between Africa and Europe may serve as a basis for phenotypic adjustment of migration schedules of trans-Saharan migratory birds. Glob Change Biol 14:250-263

Saino N, Ambrosini R, Rubolini D, von Hardenberg J and others (2011) Climate warming, ecological mismatch at arrival and population decline in migratory birds. Proc $\mathrm{R}$ Soc Lond B 278:835-842

Saji NH, Goswami BN, Vinayachandran PN, Yamagata T (1999) A dipole mode in the tropical Indian Ocean. Nature 401:360-363

Schlaepfer MA, Runge MC, Sherman PW (2002) Ecological and evolutionary traps. Trends Ecol Evol 17:474-480

Shirihai H, Yosef R, Alon D, Kirwan G, Spaar R (2000) Raptor migration in Israel and the Middle East: a summary of 30 years of field research. International Birdwatching and Research Centre, Eilat

Shobrak M (2011) Bird flyways and stopover conservation sites in the Arabian Peninsula. Zool Middle East (Supp 3): $27-30$

Stenseth NC, Ottersen G, Hurrell JW, Mysterud A and others (2003) Studying climate effects on ecology through the use of climate indices: the North Atlantic Oscillation, El Niño Southern Oscillation and beyond. Proc R Soc Lond B 270:2087-2096

Studds CE, Marra PP (2011) Rainfall-induced changes in food availability modify the spring departure programme of a migratory bird. Proc R Soc Lond B 278:3437-3443

Tøttrup AP, Klaassen RHG, Kristensen MW, Strandberg R and others (2012) Drought in Africa caused delayed arrival of European songbirds. Science 338(6112):1307

- Verhulst S, Nilsson JA (2008) The timing of birds' breeding seasons: a review of experiments that manipulated timing of breeding. Philos Trans R Soc Lond B 363:399-410

- Walther GR, Post E, Convey P, Menzel A and others (2002) Ecological responses to recent climate change. Nature 416:389-395

Zduniak P, Yosef R, Sparks TH, Smit H, Tryjanowski P (2010) Rapid advances in the timing of the spring passage migration through Israel of the steppe eagle Aquila nipalensis. Clim Res 42:217-222 